\title{
Pasiones políticas e imperialismo: la polémica entre Ginés de Sepúlveda y Bartolomé de las Casas
}

\author{
SANDRA ChAPARRO *
}

\begin{abstract}
RESUMEN
Durante siglos el "amor» se ha venido considerando una virtud política, sostenedora de la vida comunitaria y fuente de la solidaridad social. Como tal, se trata de una pasión que se encuentra en la base de los sistemas simbólicos del pensamiento político occidental, si bien hoy, pasiones y política parecen dos conceptos alejados entre si. No obstante, en un mundo en vias de globalización resurgen con fuerza términos como solidaridad o cooperación, conceptos que implican una buena dosis de "amor político". El objeto de este trabajo es recurrir al ejemplo histórico como una buena manera de señalar los riesgos y limitaciones de esta estrategia. Así, en él se analizan los debates suscitados en el siglo xvi en torno a la forma correcta de cristianizar a las sociedades indígenas
\end{abstract}

\section{ABSTRACT}

For centuries, “love» as been a political virtue enhancing communitarism and social solidarity. As such, it as been a passion we find in the basis of the symbolic systems of wesern political thought, though nowadays passions and politics seem to be different realities. Nevertheless, in a world in wich globalization process take place, concepts based on "political love» like solidarity or cooperation recover their original force. The aim of this study is to appeal to an historical example to show the risks and limits of certain kinds of globalization strategies. This article is about the debates that took place in the sixteenth century, when jurists and theologians had to decide which was the right way of christianizing

* Universidad Autónoma de Madrid. 
americanas a través de la polémica entre el "universalismo benevolente» de Bartolomé de las Casas y la idea de "cruzada como acto de amor» de Ginés de Sepúlveda. Esta polémica histórica resulta ser un magnifico ejemplo de la disputa en torno a la correcta utilización de las "pasiones politicas». american natives. The historical debate between Bartolome dse las Casas and his concept of "benevolent universalism" and Gines de Sepúlveda and his idea of a "crusade as an act of love" constitutes a great example of what can be meant by the correct use of «political passions».

\section{INTRODUCCIÓN: PASIONES POLÍTICAS}

"Sí, conozco los crímenes que voy a realizar, pero mi pasión es más poderosa que mis reflexiones, y ella es la mayor causante de males para los mortales".

Euripides: Medea (1078-1081)

En este corto fragmento de la Medea de Eurípides se condensan prácticamente todas aquellas razones que han convertido a las pasiones humanas en algo a desterrar del mundo del orden social y político de Occidente. De hecho, en este nuestro siglo XXI, la idea de que las pasiones puedan erigirse en el fundamento de una sociedad bien ordenada resulta cuando menos sorprendente. Tendemos a pensar que las pasiones son factores de turbación. Las consideramos fuerzas incoritrolables que hacen acto de presencia en los momentos más inoportunos e inesperados, contra las que debemos luchar para evitar que empañen nuestra razón y nuestra capacidad de juicio. En nuestra acepción actual las pasiones son deseos, los deseos nos incitan a «abandonarnos", a "dejarnos llevar", en definitiva, a perder el autocontrol. Pero para el hombre actual, perder el autocontrol significa perder su libertad.

Parece asi que deberiamos hacer caso a Eurípides y ponernos en guardia contra "pasiones que matan" como el amor. Porque Medea está a punto de cometer crímenes sin nombre en aras del Amor con mayúsculas, del Amor Absoluto. Desesperada ante el abandono de su amado Jasón, Medea decide asesinar a los hijos que tienen en común, sabedora de que así Jasón y ella quedarán unidos para siempre si no en el amor, sí al menos en el dolor compartido por la muerte de los niños. Poseída de una pasión que obnubila su capacidad de juicio y reflexión, sufre el peor de los tormentos: el de oír las advertencias de la razón sin ser capaz de obedecer los mandatos de la razonabilidad. A punto de poner en práctica una decisión trágica y terrible, sólo en- 
cuentra un vago consuelo en el hecho de que lo que a ella le ocurre es propio de todo mortal. Por más que lo intenten, los hombres no pueden luchar contra las pasiones, esa parte de su ser que turba y paraliza la razón creando caos a su alrededor.

Partiendo de reflexiones como las plasmadas en la gran tragedia de Eurípides, los griegos buscaron soluciones para lo que se convertiría en una de las cuestiones clave del pensamiento occidental tanto griego como romano o cristiano: la forma de controlar las pasiones, de aprovechar su potencial productivo para la percepción del mundo y la convivencia. Porque aun siendo conscientes de la naturaleza destructiva de las emociones desatadas, entendian al ser humano como un compuesto de razón y pasión, como un sujeto desiderativo capaz de fijarse las más altas metas morales movido por el amor, la compasión o la piedad.

Si bien consideramos peligrosas a las pasiones, pocos de entre nosotros seríamos partidarios de intentar extirparlas. Desde la época de la llustración griega hemos considerado al amor fuente de la vida social y política por paradójico que esto pueda sonar. Porque la pasión amorosa es impensable en soledad. El amor supone compartir y el compartir significa ser capaces de vivir partiendo de un horizonte de reglas y valores comunes, de vivir en sociedad. Cuando esta sociedad se organiza políticamente, tiende a "racionalizar» el amor que está en su origen, a dotar de fuerza a sus facetas más creativas minimizando sus capacidades destructivas. El amor se convierte en una virtud política, en una disciplina que mantiene la vida comunitaria potenciando la comunicación y la reciprocidad. Es, al fin y a la postre, una pasión unificadora, y la política es el arte de la unificación por excelencia que busca la unidad a partir de lo múltiple. El amor políticamente expresado como vínculo de unión entre seres humanos se convirtió ya, en los albores de la filosofía y la teología política, en uno de los símbolos más poderosos de las sociedades occidentales. Daba vida a la idea de una unidad que no poseía ni posee forma o sustancia palpables. La polis, la civitas, el regnum, el estado no son sino abstracciones que deben ser personificadas para ser percibidas, para poder teorizar sobre ellas, para comprenderlas y articularlas. El amor entendido como vínculo se convirtió así en un punto de partida imprescindible para la teoría política, conectando unidades a estructuras, creando cuerpos políticos que se pudieran poner en relación con el resto del mundo orgánico. Es una pasión que se encuentra en la base de los sistemas simbólicos del pensamiento político occidental. Sistemas que, como 
afirmara Clifford Geertz, no constituyen únicamente secuencias lógicas, sino que también provocan sentimientos ofreciendo la seguridad de un mundo formulado y conocido, dirigiendo nuestra sensibilidad de percepción por los derroteros marcados por la tradición que cada cual consideramos como propia.

Si aceptamos la validez de este discurso, ¿qué es lo que provoca hoy una cierta sensación de ajenidad al formularlo? Parece que la conjunción de los términos amor y político es contradictoria en el mundo actual. Estamos acostumbrados a pensar el mundo desgajado en dos: en una esfera de lo público en la que se despliegan las virtudes propiamente políticas y una esfera de lo privado en la podemos dar rienda suelta a nuestras emociones y pasiones que serían la antítesis de todo lo políticamente valioso. Desde hace unos cuantos siglos, las sociedades occidentales, alertadas tal vez por el mito de Medea, consideran que el amor es una fuerza irracional capaz de engañarnos o distraer nuestra atención de los asuntos sociales y políticos realmente relevantes. Algo que debe quedar en todo caso relegado al ámbito oscuro de lo privado, ese locus donde los seres humanos interactúan para ver cubiertas sus necesidades físicas y materiales. Consideran los detractores del amor político que el juicio en la esfera de lo público no puede hacerse depender de una fuerza que es afectiva y no cognitiva; que se muestra en exceso vinculada al mundo de lo instintivo y carece de racionalidad. Sin embargo, una parte nada desdeñable de la tradición filosófico/religiosa occidental abarca un conjunto de preguntas y respuestas destinadas a aclarar un concepto tan básico para nuestra forma de vida, que no ha sido posible desecharlo a pesar de los riesgos que comporta su reconocimiento como pilar de la vida en común.

Quienes entienden de amor, afirman que no se trata sólo de una fuerza impulsiva, ya que siempre implica un elemento intelectivo que surge a partir de nuestras creencias y valores. Amamos aquello que consideramos digno de ser amado, aquello que valoramos. Para que alguien se convierta en amable a nuestros ojos debe ser posible establecer algún tipo de comunidad entre ese alguien y nosotros, porque difícilmente compartiremos nuestro amor con lo que nos resulta tan ajeno que tan solo suscita en nosotros indiferencia o, todo lo más, curiosidad. El establecimiento de la relación amorosa implica así necesariamente juicio, elección, decisión. Supone elegir aquello que queremos querer, delimitar objetivos, emitir juicios sobre el tipo de mundo que queremos construir. $Y$ si al amar juzgamos, debemos concluir que existe asimismo una íntima vinculación entre el amor y la justicia. 
El debate sobre el amor refleja dos visiones totalmente diferentes de la comunidad política ideal y del buen ciudadano. Sin embargo, no se trata de un diálogo entre los partidarios de la razón y los de algún tipo de fuerza oscura e irracional. El debate en torno al amor es un debate sustantivo sobre los valores éticos de la comunidad. Ambos modelos pretenden realzar la dignidad humana y defender la libertad y la igualdad. Defensores y detractores son conscientes de que amar es juzgar pero discrepan sobre la veracidad y fiabilidad de los juicios que se adoptan a través de la fuerza empática que genera el compartir emociones.

La misma existencia de esta polémica en torno al potencial político de pasiones como el amor, la solidaridad o la compasión demuestra que, por más que intentemos domesticarlas y relegarlas a espacios invisibles, las emociones nunca han dejado de estar presentes en el pensamiento occidental sobre lo público. Podemos rastrear su presencia en toda una serie de movimientos y tendencias de profundo significado filosófico y político como el romanticismo, el nacionalismo, el comunismo, el anarquismo o el fascismo. Es más, las pasiones como base del actuar público conjunto de individuos y pueblos están hoy día más vivas que nunca. Porque a pesar del rechazo a la emotividad política generada por la difusión y el alcance del terror nazi o estalinista; a pesar de la enorme capacidad para la indiferencia que hemos aprendido a desarrollar los habitantes del mundo postindustrial ante esas imágenes televisadas diariamente en las que se reflejan el horror y la muerte, seguimos propugnando (oficialmente al menos) la necesidad de fundamentar nuestro actuar en tanto que individuos y comunidades en valores como la solidaridad, la amistad o la cooperación. Conceptos todos ellos que han venido a sustituir en el vocabulario político al uso a términos de raigambre menos secularizada como el amor o la caridad. Bien es cierto que se podría argumentar que la equivalencia nunca es exacta y que, por ejemplo, cooperación o solidaridad son conceptos cuyo referente emotivo es menos intenso y está más racionalizado o «domesticado». No es este lugar para entrar en una polémica de este tenor. Sí se podría señalar que, si bien existen diferencias entre estos conceptos, lo que no se podrá negar es que todos ellos forman parte de lo que Walter Benjamin denominaría una "constelación de conceptos" y que comparten ese famoso "aire de familia" del que Wittgenstein hablara en su día. Parece así que en un mundo cada vez más dominado por fuerzas de signo contrapuesto como el individualismo por un lado y las tenden- 
cias globalizadoras por otro, prolifera la cooperación con individuos y pueblos desfavorecidos, explotados o humillados. Las sociedades occidentales, bien a través de instancias estatales o por medio de organizaciones de ayuda no-gubernamentales pretenden llevar un mayor bienestar y una concepción de la justicia basada en la implantación de los derechos humanos hasta los últimos confines del globo. Probablemente, una vez agotada la lucha por los derechos civiles de los años ' 60 del siglo $\mathrm{xx}$, donde con mayor fuerza haya rebrotado la idea de amor político haya sido en el ámbito del derecho internacional y la extensión de los derechos humanos.

Es esta constatación la que me ha hecho fijarme en otro momento del tiempo y el espacio en el que tuvo lugar una polémica jurídico-político de significación similar. Me refiero a la polémica sobre la evangelización de las Indias que tuvo lugar en el ámbito de la monarquía hispana a mediados del siglo XVI. Al inscribirse en el marco de una discusión temática más amplia en la que se consideraban aspectos sobre justos títulos de dominio y propiedad, posibilidades de explotación económica de los recursos, problemas de jurisdicción etc., la argumentación ético-política en torno a las posibilidades y la forma correcta de llevar a cabo la cristianización de las sociedades indígenas tal vez haya quedado algo oscurecida. Quisiera, en las páginas que siguen, destacar algunos aspectos de esta polémica que tuviera lugar entre Ginés de Sepúlveda y Bartolomé de Las Casas por considerarla un magnífico ejemplo de disputa en torno a la correcta utilización de las pasiones políticas. Considerando los argumentos de ambas partes creo que se puede llegar a la conclusión de que en la base de ambas formulaciones se esconde un concepto que, a estas alturas, ya debe resultarnos familiar: el amor político. En este debate no se pone en tela de juicio que el amor deba ser el fundamento de un sistema político. Es bien sabido que la neo-escolástica salmantina de la época, siguiendo a Agustín de Hipona y a Tomás de Aquino, hacía del amor la primera de las virtudes políticas. Solo que cada uno de nuestros autores entiende de forma diferente el modo de dar expresión a ese amor a la hora de enfrentar los problemas generados por el contacto con otras culturas educadas en tradiciones profundamente diferentes. Tal vez el análisis de sus argumentos nos permita comprender mejor, a los hombres y mujeres de hoy, las ventajas y riesgos que se esconden tras las distintas formas de entender el amor corno pilar básico de ese puente que, inevitablemente tendremos que tender hacia las demás culturas que pueblan el globo. 
Pasiones políticas e imperialismo: la polémica entre Ginés de Sepúlveda...

\section{BARTOLOMÉ DE LAS CASAS: EL UNIVERSALISMO BENEVOLENTE}

"Los reyes son obligados por los medios cristianos a conseguir la honra y gloria del divino nombre y plantación de la fe y salvación de todas aquellas ánimas por la predicación del evangelio dulce, amorosa y pacífica. Ir las guerras delante del evangelio es ponerse en todo aborrecimiento y odio de los infieles el nombre cristiano y el mismo Cristo...".

Bartolomé de Las Casas: Tratado tercero, quinta réplica ${ }^{1}$

En la primera mitad del siglo $x \mathrm{VI}$, los teólogos hispanos hubieron de enfrentarse a un problema práctico de proporciones gigantescas. Este siglo bien se puede decir que supone los inicios de una nueva época para las relaciones internacionales, marcada por la aparición en Europa de los estados nacionales y su expansión colonial ${ }^{2}$. Es una época de rápidos cambios socio-políticos, económicos y tecnológicos que crean una nueva conciencia de temporalidad y contingencia. Así como en el ámbito de la redefinición práctica del modelo de amor tomista, los maestros neo-escolásticos hispanos hubieron de enfrentarse a escotistas y protestantes, en el campo de la reformulación de las relaciones internacionales tuvieron por antagonistas fundamentales a los defensores del realismo pragmático de corte maquiaveliano ${ }^{3}$. Asistimos así en efecto a la pugna entre dos modelos de civilización totalmente distintos, tanto en sus objetivos como en los medios utilizados para lograr esos objetivos. Porque frente al modelo medieval en el que los actores son comunidades religiosas enfrentadas entre si en guerras santas cuyo fundamento último se encuentra en un universalismo idealista, los realistas plantean un universalismo alternativo, basado en la ciencia, el utilitarismo y la economía política. Una tradición ésta que distaba también mucho de ser nueva, ya que podemos retrotraer sus orígenes hasta Tucídides. El gran historiador griego resumiría esta postura en el libro I de Las guerras del Peloponeso

\footnotetext{
En Hanke, L. y Gimenez Fernández, M., (edts.), Tratados de Bartolomé de Las Casas. Méjico, 1965, I, p. 365.

2 Cfr., sobre estos aspectos, ORTEGA, M.C., "Vitoria and the universalist conception of international relations", en CLARK, I.(edt), Classical Theories of International Relations.. Oxford, 1999, pp. 99-119.

3 Sobre el modelo teológico-político de la Escuela de Salamanca, vid., Chaparro, S., "La reformulación del universo teclógico/político por la Escuela de Salamanca en el siglo xvl», Mimeo, 2000.
} 
al afirmar que "siempre ha sido normal que el más débil sea reducido a la obediencia por el más poderoso" y que, "aceptar un imperio no es nada digno de extrañeza ni fuera de la naturaleza humana» ${ }^{4}$. Esta tradición pragmática se basaría en la idea de que los imperios se conquistan por imperativo natural, pero el ejercer en ellos la justicia no depende de la necesaria aplicación de leyes naturales o divinas de carácter universal, sino de la mera voluntad de los conquistadores ${ }^{5}$. El nuevo pensamiento de corte realista aplicado a la política exterior reflejaría así las consecuencias políticas de la ruptura del universo teológico medieval, la pérdida de la fe en una historia universalista ${ }^{6}$, en la que cada pueblo cumple su papel para la realización de los planes de la Divina Providencia.

Los pensadores neo-tomistas, enfrentados a la necesidad de justificar el dominio hispano sobre los pueblos de las recién descubiertas Indias Occidentales optarán, no obstante, por mantenerse en una línea universalista medieval tradicional mucho más acorde con su concepción de la política como algo fundamentado en aspiraciones universalistas. Haciendo de la armonía el valor clave, defenderán el imperio como medio para la ordinatio mundi, la concordia hominum y la defensa fidei, de acuerdo con un programa internacional dirigido a la restauración y ampliación de la universitas christiana. Para ello recurren nuevamente a fundamentos de tipo legal y definen el ius gentium elaborado por la doctrina jurídica romana como aquello que está constituido por la razón natural entre los hombres. La idea es que si todos los hombres son seres racionales, todos, por ajena que pudiera resultar su civilización, estarían unidos por unas normas cuyos preceptos podrían ser percibidos como verdaderos por todo ser racional. El derecho de gentes no precisa así para su establecimiento ni de príncipes ni de asambleas públicas que lo estatuyan porque es la misma razón natural la que lo enseña a los hombres ${ }^{7}$.

4 Es el famoso discurso de los atenienses en defensa de su imperialismo ante la Asamblea lacedemonia recogido en Las guerras del Peloponeso, I. 73-78. Las frases citadas se encuentran en el párrafo 76. La traducción que he utilizado es la de Francisco Rodríguez Adrados en la edición de Hernando, Madrid, 1984.

5 Para este argumento, ampliado, Cfr., ORWIN, C.,: "Justifying the Empire: The speech of the Aithenians at Sparta and the problem of justice in Thucydides", Journal of Politics, 48 (1986), pp. $72-85$.

6 En palabras de WALKER, R.B., Inside/Outside: International Relations as Political Theory. Cambridge, 1993, pp. 30-45.

7 Vid. DOMINGO DE SOTO, De iustitia et de iure, lib. IV, quest. 3, art. 1: «... hac namque ratione ius gentium differt a civili quod scilicet ratio ipsa in singulos seorsim homines illud docet». La edición consultada es la del IEP, Madrid, 1967. 
El cristianismo bebe en las fuentes del estoicismo helenista, y hace suyas unas normas básicas de conducta referentes al derecho de la guerra y la inmunidad de los embajadores que supone aceptadas por todos los pueblos del mundo. Porque si el ser humano se caracteriza por ser capaz de deliberar racionalmente y expresar el resultado de esa deliberación por medio del lenguaje, cabe asumir que todos los hombres, sean o no cristianos, coexisten en la razón y tienden a la comunicación de ciertas normas básicas y consustanciales a su condición de seres humanos.

Eso sí, los pueblos cristianos (que gozan de una "moral superior») estarian obligados según Francisco de Vitoria a predicar el mensaje de amor de los Evangelios porque «la corrección fraterna es de derecho natural como el amor y y a cada uno confió Dios el cuidado de su prójimo ${ }^{8}$. Los príncipes del nuevo Mundo deben permitir la predicación pacífica según las normas del derecho de gentes, para que se ilumine su razón. En palabras del humanista español Hernán Pérez de Oliva, los cristianos cumplirian su providencial misión de "unir el mundo y dar a esas tierras extrañas la forma de las nuestras" ${ }^{9}$. Vitoria introduce así el amor/caridad, típico fundamento cristiano de la comunidad política, como concepto a regir igualmente las relaciones entre sociedades políticas diversas. La caridad universal está llamada a servir de aglutinante entre hombres y sociedades y entre éstas y el orden cósmico ${ }^{10}$. Quienes han alcanzado un mayor desarrollo moral deben predicar las rectas normas de conducta a los demás para que éstos, iluminados por la razón de amor entren a formar parte de la república cristiana cuyos miembros creen en la salvación de sus almas. La conquista se convierte en un deber moral y la fuerza de la razón y el amor deben hacer innecesaria la violencia y el temor, al igual que convertían en innecesaria la compulsión entre cristianos ${ }^{11}$.

8 Vid. Francisco de Vitoria, De Indiis, Relección Primera, punto 9. Edición de T. Urdanoz, Madrid, 1960.

9 Esta frase se encuentra en una carta escrita al almirante Colón justo antes del comienzo de su segundo viaje citada en ELLIOT, J.H., The Old World and the New, 1492-1650. Cambridge, 1972, p. 15.

10 En verdad Vitoria refleja en este punto la idea de la caridad universal entre los cristianos desarrollada in extenso por Erasmo de Rotterdam en el capítulo I de su Enchiridion. Vid., por ejemplo, p. 116 de la edición de D. Alonso, Madrid, CSIC, 1971.

11 Muchos autores han señalado como las teorías de Vitoria legitimaban teológicamente los intereses españoles. Sin embargo lo cierto es que, oficialmente al menos, se tendía a reiterar que también se favorecian los intereses de los indígenas. Asi Vázquez de Menchaca afirmaba que se había elaborado «una doctrina beneficiosa para aquellos a los que se mal- 
El modelo es una clara trasposición de las ideas de los neo-escolásticos sobre la comunidad política ideal. Sin embargo, los miembros de la escuela se verían divididos, no sobre el fondo sino sobre la forma adecuada de lograr la iluminación y conversión de los habitantes del Nuevo Mundo al mensaje de fe y amor que les llevaban los cristianos. Fray Bartolomé de las Casas afirmaría que los conquistadores, desvirtuando el modelo de amor y caridad cristianas que decían defender hacian la guerra a los indios y les privaban de su libertad en su propio beneficio. En su opinión, la libertad sería un derecho natural porque al dotar Dios a los hombres de libre albedrío, quien perdiera su libertad perdería al mismo tiempo su alma ${ }^{12}$. Rechaza así enérgicamente la teoría aristotélica de la esclavitud natural y recuerda a los príncipes cristianos que el derecho natural les obliga a proveer siempre al buen y recto gobierno y a administrar justicia de forma que puedan ser llamados justamente «padre» y «pastor» ${ }^{13}$. Podría resumirse así su postura alegando que quien defiende un modelo de cohesión basado en el amor y la no-violencia, difícilmente puede resultar convincente intentado imponerlo mediante la guerra y el terror. Esgrime diversos argumentos a favor de su postura. En primer lugar considera que la afirmación contenida en el Evangelio de Lucas ${ }^{14}$ según la cual sería lícito «obligar a quienes no lo desean a entrar en la lglesia» se referiría a los herejes no a los infieles, aparte de que la compulsión consistiria en obligarles a escuchar las exhortaciones no a hacerles la guerra ${ }^{15}$. En su opinión, si el Nuevo Testamento brindó a los hombres un mensaje de amor, difícilmente podrán hacerlo realidad por medio de matanzas. El cristianismo debe ser, afirma, religión de paz apoyada en la palabra y las batallas que libre deben ser verbales porque, ¿cómo van a desear los indios adoptar la religión de aquellos que les matan? ${ }^{16}$ Esta sería la tónica general del cristianismo que

trataba». Vid. Rodríguez Alcalde, F., (ed). Controversiarum illustrium, 1.10.12, Valladolid, 1931, citado en ORTEGA, Vitoria and the universalist conception..., p. 114. Un debate actual sobre el tema se puede encontrar en WILLIAMS, R.A., The American Indian and Western legal Thought. Nueva York, 1990, pp. 326 y ss.

iz Vid. BARTOLOME DE LAS CASAS, De regia potestate, I,.1-5, en J. González Rodríguez (ed), Obras completas de B. De las Casas. Madrid, 1990, vol.12.

13 LAS CASAS, De Regia..., XIX.2 y XXII.5.

14 Lucas 14.23.

15 Vid. Bartolomé de las Casas, Tratados. Vol. I, Méjico, FCE, 1965. La referencia corresponde al Tratado Tercero, p. 241.

16 Vid. LAS CASAS, Tratado tercero, réplicas 1 a 4, pp. 337/361 de la edición citada. 
hallaría apoyatura bíblica incluso en el Antiguo Testamento en el cual se prohibe matar a los inocentes ${ }^{17}$.

Hasta aquí Las Casas esgrime una argumentación de fuertes connotaciones bíblicas. Sin embargo, la alusión a los inocentes le sitúa ante la necesidad de demostrar que los indios entran en la categoría de «inocentes». Aduce aquí un argumento con fuertes connotaciones aristotélicas, a saber: que no se puede culpar a los pueblos por seguir sus propias tradiciones, por adoptar las costumbres que los más sabios y prudentes de entre ellos consideran más justas. Esta se convertirá, como veremos, en la clave de toda la polémica con Sepúlveda. Para exponer y desarrollar su argumento, Las Casas no puede por menos que referirse a Aristóteles. En su Tratado Tercero ${ }^{18}$ el obispo de Chiapas afirma lo siguiente: «Aquella es probable opinión según Aristóteles en el primero de los Tópicos, la que tienen los hombres más sabios. Y en el principio de la Retórica, capítulo 2 también dice que aquello se ha de tener que opinan los más prudentes. $Y$ como aquellas naciones donde este error reina, los sabios de ellos y los sacerdotes y reyes y sus pasados así se lo hayan enseñado, tienen por ende alguna excusa hasta que los enseñen la verdad" ${ }^{19}$. El argumento sorprende, en primer lugar, por ser la única referencia que nuestro fraile/obispo hace al maestro peripatético. En segundo lugar porque parece ampliar los límites de la tolerancia cristiana hasta dimensiones inexploradas, dando entrada aquí a un reconocimiento inesperado al valor de tradiciones culturales diferentes. La sensación de ajenidad que pueda despertar esta alusión en el seno de la argumentación general desparece no obstante al retomar Las Casas una cadena de pensamiento más afín al modelo neo-escolástico general basado en la caridad cristiana y la salvación por las obras propugnada por Vitoria y de Soto ${ }^{20}$. Así, cierra su exposición afir-

$17 \quad$ Exodo 23.7

18 Op. cit., p. 277.

19 Efectivamente Aristóteles asi lo afirma en Tópicos, 100b20ss y Retórica, II.1395a $10 \mathrm{ss}$.

20 El modelo de Vitoria y de Soto surge, como es sabido, en un momento en que el luteranismo propugnaba la salvación por la fe, negando toda importancia a este respecto a las buenas obras. En contra de esta idea los maestros de Salamanca emprenden una entusiasta redefinición del amor como virtud política. El amor político debe ser además, en su opinión, un amor activo y no místico (San Agustín) o intelectual (Tomás de Aquino). Un amor a ejercer por todos los cristianos de una república cristiana que se precie de tal nombre. Una virtud activa, interpretada en clave aristotélica, pero reelaborada más allá de los límites de Aquino. Al respecto vid. Chaparro, Retormulación del universo teológico-politico.... 
mando que «optar por la vía del amor...supone elegir la vía pacífica, amorosa y cristiana, ganando por amor y por buenas y oficiosas obras los ánimos y voluntades de aquellas gentes" ${ }^{21}$. Sin embargo, el argumento basado en la idea aristotélica de tradición no pasará desapercibido a un gran experto en Aristóteles como Juan Ginés de Sepúlveda, que utilizará esta idea avanzada por Las Casas para volverla en su contra y apuntalar sus propios argumentos. Veámoslo.

\section{GINÉS DE SEPÚLVEDA: PEDAGOGÍA DESPIADADA O LA CRUZADA COMO ACTO DE AMOR}

"Nosotros no decimos que a estos indios idólatras se les ha de hacer la guerra para matarlos y destruirlos...sino para subjetarlos y quitarles la idolatría y malos ritos, y quitar los impedimentos de la predicación evangélica".

Juan Ginés de Sepúlveda: Segunda objeción alegada ante la congregación de teólogos y juristas convocada por su Majestad, Carlos V en Valladolid, $1552{ }^{22}$

Por su lado, Juan Ginés de Sepúlveda defenderá la necesidad de hacer la guerra a los indios con argumentos que también hallan firme apoyatura en el modelo neo-tomista de los salmantinos. Sepúlveda empieza definiendo la ley natural como aquella que deriva de la ley eterna y percibimos por medio de la razón según "la luz divina impresa en nuestros corazones" ${ }^{23}$. Al rey se le ha concedido la facultad de interpretar la adecuación de la ley natural a la ley eterna para que pueda mirar por el bien y la prosperidad de los suyos y pueda ser amado por los súbditos ${ }^{24}$. La caridad es el vínculo político básico y, además, ocupa el primer lugar por lo que se refiere al merecimiento de la vida eterna ${ }^{25}$. El príncipe cristiano es por tanto amado porque procitada.

21 LAS CASAS, Tratado Tercero, réplica duodécima, p. 435 de la edición de los Tratados

22 Vid. Ginés de Sepúlveda en la segunda objeción que hace en su prólogo a los señores de la Congregación, recogido en HANkE y GIMÉnez FERnÁndez, Tratados de Fray Bartolomé de las Casas..., I, p. 291.

23 Gines de SePulveda, Del reino y los deberes del rey, en Tratados políticos, Madrid, 1963. La cita corresponde a I.19, p.54.

24 Del Reino..., !.11, p. 44.

25 Es decir, se muestra a favor de la salvación por las obras. Vid., Del Reino..., I.19, p. 56. 
cura bienestar y libertad a sus súbditos. Encarna la causa pública de la cristiandad que consiste en "luchar por la libertad de los cristianos" ${ }^{26}$. Esta obligación deriva directamente de los Evangelios donde ante la pregunta de lo que se debía hacer para conseguir la vida eterna Jesús responde que guardar los mandamientos, entre ellos el mandamiento de caridad que consiste en amar al prójimo como a uno mismo ${ }^{27}$. Los cristianos deben pues defender la integridad de su República castigando a los transgresores tanto más duramente cuanto que "la santidad y la religión son más excelentes que los bienes de este mundo" ${ }^{28}$. Sepúlveda cierra su Demócrates Primero citando en su favor a San Agustín, según el cual aquel a quien se le quita la licencia y el poder de hacer el mal es vencido en provecho propio. Entendía el obispo de Hipona que los cristianos no debían retroceder ante la necesidad de ejercer un deber de corrección que acababa aprovechando a aquellos por cuya salvación se velaba al llevarles por el camino de la concordia y la armonía propia de las enseñanzas cristianas. El deber de corrección probablemente fuera uno de los más duros impuestos por Dios a sus fieles, pero había que considerarlo una medicina, un remedio que aplaca y cura a quienes se ven afectados por lo que evidentemente resulta ser una desviación de la conducta correcta y saludable para él mismo y para el resto de la comunidad ${ }^{29}$. Aduce a su favor asimismo la autoridad de San Pablo cuando señala que a los príncipes seculares no les es dado portar las armas en vano. La espada no sería sino una servidora de Dios para infligir el castigo a quien comete el mal ${ }^{30}$.

La imagen de la república cristiana diseñada por Sepúlveda refleja así una comunidad de guerreros militantes, con fuertes connotaciones medievales, basada en la idea de que todo cristiano lleva dentro de sí a un soldado de Cristo. Es una imago presente desde los primeros tiempos del cristianismo que encontramos, por ejemplo, en el prólogo de la Regla de San Benito donde se alude a aquellos cristianos que «esgrimen las po-

26 Asi en Demócrates Primero o diálogo sobre la compatibilidad entre la milicia y la religión cristiana en Tratados políticos, Madrid, 1963. La cita está en el párrafo 4, pp. 141-2.

27 Vid. Mt. 19. 16-19. La cita del Demócrates Primero está en el párrafo 17, p. 160 de la edición citada.

28 Demócrates Primero, pfo. 22, p. 168.

29 La postura de San Agustin respecto de este problema es bien conocida. Las referencias a las que se alude en el texto pueden encontrarse en la carta 138 dirigida a Marcelino contenida en Obras completas de San Agustín. BAC, Madrid, 1987, Vol. Xla.

30 La cita de San Pablo es el famoso: "Princeps non sine causa gladium portat" de Rom.XIII.4. 
tentísimas armas de la obediencia para servir al verdadero rey, Cristo el Señor " ${ }^{31}$. Probablemente, la culminación del modelo de una república cristiana compuesta por guerreros dispuestos a luchar contra el mal con todas las armas a su alcance esté en Bernardo de Claraval y su Elogio de la nueva milicia templaria. Con esta breve obra Bernardo contribuyó enormemente a dotar de legitimidad teórica a la mayor empresa guerrera medieval de la cristiandad: las Cruzadas. San Bernardo se muestra a favor de desenvainar la espada, tanto espiritual como material, para acabar con todos aquellos malhechores que pretenden levantar torreones contra el conocimiento de Dios que es la fe cristiana. Porque la fe, no es sólo un problema interno del Orbe. El cristianismo debe exhibirse orgulloso ante las demás naciones del mundo de modo que no quepa la posibilidad de que éstas pregunten: “¿Dónde está su Dios?»32.

Sobre estas bases desarrollará nuestro pensador su defensa de la guerra contra los indios. Siguiendo la lógica implacable del modelo de amor cristiano, Sepúlveda afirma que todas las leyes naturales y divinas que rigen las conductas de los hombres tienen por misión mantenerles en el cumplimiento de sus deberes, conservar en esta vida la sociedad humana y hacer de ella una escala para la vida eterna. La sociedad cristiana debe fundarse sobre la mutua caridad y la benevolencia. Por caridad debe entenderse la piedad y el amor a Dios. Pero el amor a Dios se cifra principalmente en la observancia de sus leyes. Leyes que se contienen fundamentalmente en el decálogo que da forma al derecho natural (del cual el ius gentium es una parte) fundamentando el orden de las sociedades humanas ${ }^{33}$. Partiendo de estas bases Sepúlveda entrenta la cuestión de qué deben hacer los cristianos ante el encuentro con pueblos que, desconociendo el orden justo de la ley natural profesan costumbres tan bárbaras que «impidan que sus espíritus puedan recibir la religión de Cristo» ${ }^{34}$. ¿Se les puede

31 Vid. Colombas, G.M., e Aranguren, I., (eds), La regla de San Benito. Madrid, 1993. El texto original del prólogo reza asi: "Ad te ergo nunc mihi sermo dirigitur, quisquis abrenuntians propriis voluntatibus, Domino Christo vero regis militaturus, obedientiae fortissima atque praeclara arma sumis".

32 Vid. San Bernatdo de Cl.araval, Elogio de la nueva milicia templaria. Madrid, Siruela, $1994,111.5$.

33 Vid., Democrates Segundo, I.3.

34 Esta forma de plantear la cuestión se encuentra en la carta introductoria a la Apología a favor del libro sobre las justas causas de la guerra, en A. MORENo (edt.), Obras completas de Juan Ginés de Sepúlveda, Pozoblanco, 1997. pg.195. 
obligar a creer en los preceptos que salvarán sus almas? Sepúlveda introduce en este punto la idea de que es propio del derecho natural (y por tanto del orden mismo de las cosas) que los menos prudentes y sabios obedezcan a los más prudentes y capaces. En apoyo de su tesis cita numerosos pasajes de la Biblia, además de las obras de autores tan reputados como Aristóteles, Agustín de Hipona o Aquino ${ }^{35}$. En verdad el texto definitivo es el de Aquino que se pronuncia en la Suma de teología a favor de que los fieles remuevan todo obstáculo a la fe. Admite que se pueda dominar a los infieles mediante la guerra santa no para que crean (no se puede obligar a creer) sino para impedir que obstaculicen el desarrollo de la fe ${ }^{36}$. Sepúlveda defiende así la necesidad de hacer la guerra a los indios alegando que se trata de una nación que atenta contra los preceptos de la ley natural con su idolatría y su costumbre de practicar sacrificios humanos. Esta costumbre bárbara se convierte en intolerable para cualquier pueblo «civilizado» cuando se trata de una práctica institucionalizada y aprobada públicamente por las autoridades en el gobierno ${ }^{37}$. Entiende que esta situación exige la aplicación de los mandamientos básicos de la caridad cristiana que obligan a mostrar el camino al errante y atraer a los paganos a la verdadera religión.

En el fondo, hasta este mismo punto Sepúlveda no discrepa de un Bartolomé de las Casas que también quería llevar el mensaje de amor cristiano a los indios. Como hombres religiosos, ambos están persuadidos de la superioridad de su orden moral y de las ventajas que com-

35 Vid. Deut. 12.31 y $18.9-12$ contra los cultos cananeos, Lev 18 y 20 en la que se alerta a los israelitas contra las costumbres de los egipcios. En el caso de Aristóteles cita Politica, III.13.1284. ${ }^{\mathrm{a} a:}$ "Si hay un solo individuo o más de uno...que destacan tanto por su ventaja en virtud que no es comparable ni la capacidad política de todos los demás con la de aquellos...no hay que considerarlos parte de la ciudad, ya que se cometerá una injusticia con ellos al daries igual derechos que a los demás...pues como un Dios entre hombres será lógicamente el de tal condición». La traducción es de Carlos García Gual en la edición de Alianza, Madrid, 1986. En el caso de Agustín, Sepúlveda cita el libro V cap. 12 de La ciudad de Dios en el que el santo afirma que el imperio romano fue querido por Dios para reprimir los graves vicios de muchos pueblos. Agustín cita a Virgilio cuando afirma que el arte de los romanos consiste en saber ejercer el dominio sobre otros pueblos, “imponiendo las normas de la paz, perdonando a los vencidos y derrocando a los soberbios". (pacique imponere morem, parcere subiectis, et debellare superbos.) Vid. la edición de la BAC con traducción de Santos Santamarta del Río, Madrid, 1988.

36 Vid. Suma de teologia, II-ll cuestión 10, artículo 8, BAC, Madrid, 1995.

${ }^{37}$ Vid. Demócrates Segundo, I.15 y Apologia a favor del libro sobre las justas causas de la guerra, 7.5 . 
portaría para los nativos su implantación. Ahora bien, puestos de acuerdo sobre la necesidad de hacer que los pueblos del Nuevo Mundo abandonen las bárbaras costumbres que condenarán sus almas, resta por decidir la forma adecuada de hacerlo. Sepúlveda, al contrario que Las Casas, no cree posible la conversión por medio de la mera predicación y del diálogo. Retomando el único argumento de Las Casas basado en teorias aristotélicas al que hacíamos alusión algunas páginas atrás, Sepúlveda afirma que los indios no hacen sino seguir su propia tradición, aquella que es considerada válida en opinión de los más sabios y justos de entre ellos. Mostrando en este punto la gran influencia que el aristotelismo de algunos de sus maestros como Pomponazzi había ejercido sobre él, Sepúlveda trae a colación en este punto el argumento completo de un Aristóteles que había afirmado que para pensar, debemos siempre partir de alguna premisa no-demostrada porque no podemos cuestionar a la vez todas las partes de un argumento científico, debemos partir de premisas que demos por supuestas si queremos llegar a alguna conclusión ${ }^{38}$. En el fondo, partimos así en el pensar sobre cualquier asunto de ciertos axiomas que no serían sino las opiniones compartidas por la mayoría o los más sabios, lo que cada comunidad según su propia tradición, considera valores dignos de defensa ${ }^{39}$. Los axiomas del saber deben discutirse por medio de la dialéctica para adquirir validez. Esta, la dialéctica, sería la forma de confrontar opiniones diversas en un ámbito público en el que cupiera defender aquello que, en opinión de cada interviniente, es la mejor plasmación lingüistica de la racionalidad que más conviene a la comunidad. Posteriormente estas premisas transmitidas por la tradición son estudiadas e interrelacionadas por la filosofía y la metafísica ${ }^{40}$. Así, tanto las ciencias como la metafísica parten de premisas acreditadas, de opiniones aceptadas por todos los miembros de la comunidad o, al menos, por la mayoría de ellos o por los más sabios. Los endoxa serían así las opiniones de personas que comparten la cualidad de ser miembros de un grupo de algún tipo, que comparten una forma de vida, una forma de ver el mundo y de plantearse los problemas y una lengua en la que formular las preguntas. Las premisas que elaboran se legitiman por el sistema de confrontar opiniones contrarias y por su

38 Vid. Afistóteles, Tópicos,101. ${ }^{a}$, 35ss., en Organon. Madrid, 1982.

Vid. Top., 100b2.0, y también Etica Nicomaquea, 1143b10-15. Madrid, 1985.

Vid. Metafísica. Madrid, 1987, líneas 1004a35ss. 
utilidad a la hora de permitirnos generar hipótesis sobre el mundo en que vivimos y el sentido que queremos darle ${ }^{41}$. La tarea de intercambio de opiniones da lugar a un corpus de principios básicos que se integran en la tradición de una comunidad. Esta tradición fija modelos de actuación y estándares que se mantienen a través del tiempo porque se suponen basados en la sabiduría de los padres fundadores. Quienes los conocen y transmiten adquieren auctoritas, ese tipo de admonición que Mommsen definiera como algo más que un consejo y algo menos que una orden ${ }^{42}$.

Estas ideas peripatéticas, recogidas por Sepúlveda aclaran bastante su postura ante la necesidad de la guerra ${ }^{43}$. Ginés de Sepúlveda afirmará que cuando se trata de incidir sobre las normas básicas de la moral que afectan a la visión general del mundo de un pueblo, no basta con predicar. Para hacer llegar el mensaje de amor cristiano es preciso primero destruir los endoxa, desmentir las tradiciones anteriores. Para lograr que los indios escuchen el mensaje divino sin prejuicios y sean por tanto capaces de entenderlo, hay que partir de cero. Así, si bien es cierto que la adquisición de la fe es un problema de voluntad, algo a lo que no se puede obligar a nadie, no es menos cierto que sí se puede obligar a escuchar el mensaje evangélico y que para ello se deben tomar las medidas previas que sean necesarias. Como afirma Sepúlveda en su apología a favor de las justas causas de la guerra, es preciso remover todo obstáculo a la fe si es necesario mediante una guerra validada por el Papa quien tiene el poder recibido de Cristo y de Pedro de obligar a los pueblos a observar la ley natural ${ }^{44}$.

41 Esta forma de interpretar la crítica de los peripatéticos a los platónicos y su idea de que el saber se fundamenta en "a prioris" que la mente más que conocer "reconoce» ha sido defendida por múltiples autores, pero con especial claridad por Martha Nussbaum en su obra The Fragility of Goodnes. Cambridge, 1986, pp. 245 y ss.

42 Vid. AREnd, H., Between Past and Future. Nueva York, 1968, pp. 17-40.

43 Se las puede encontrar en el Demócrates Primero o diálogo sobre la compatibilidad entre la milicia y la religión cristiana. En este texto define la ley natural siguiendo las opiniones de Aristóteles y Cicerón, Según la interpretación que Sepúlveda hace de estos autores es justo por naturaleza lo que en todas partes tiene la misma fuerza, aquellos principios de los que se sirven todas las naciones. Remite al libro $V$ de la Etica Nicomaquea y concluye en el libro I pfo. $\mathrm{X}$ : “ld porro ubique vim eamdem habere, docti viri interpretantur, quos est tale sponte sua, non quia sic placuerit legislatori cuipiam, aut alicui civitatis. La cita latina en Joannis Genesii Sepulvedae, Opera. Madrid, 1780, edición de la Real Academia de la Historia, vol. IV, p. 236.

44 Apología en favor del libro sobre las justas causas de la guerra..., 4.2 y 6.3 . A su favor, Sepülveda cita normativa canónica como el Decreto de Graciano, las obras de Enrique 
Según nuestro autor, los indios deben ser compelidos a la justicia para que sean capaces de asimilar la prédicas que lleven a la salvación de sus almas. La Iglesia cuenta para ello con la potencia de la espada de los príncipes cristianos que cumplen así una función muy precisa ${ }^{45}$. $\mathrm{Si}$ se impele a conocer la verdad ignorada se acaba rechazando la falsedad que se defendía y, finalmente se acaba queriendo y abrazando lo que no se quería ${ }^{46}$. Porque como afirmaba Aristóteles, difícilmente se alteran con palabras y desarraigan las cosas impresas en las costumbres y mantenidas por mucho tiempo...de donde nacieron las leyes que tienen poder coercitivo ${ }^{47}$. El amor/caridad para ser eficaz como aglutinante social y base de la política debe ser un hábito, una forma de ser arraigada en el carácter que nos permita juzgar con libertad y alcanzar la sabiduría ordenadora de la ley natural. Los miembros de la república cristiana deben estar dispuestos, con la bendición papal y la ayuda de la espada de sus príncipes, a crear las condiciones que permitan «educar» a los bárbaros en los «hábitos correctos». Porque, tal y como afirmara Aristóteles, la virtud es una cuestión de hábito, y para aprender a ser justos hay que estar habituados a practicar la justicia, no basta con escuchar las palabras de los hombres sabios. Aprendemos a construir casas construyéndolas, a tocar la flauta, tocándola y, lo que es más importante: a ser justos practicando la justicia ${ }^{48}$. Pero para practicar la justicia correctamente es preciso sentar las bases de una sociedad bien ordenada de acuerdo con los preceptos del derecho natural. Así, en el caso de los indios, no hay más remedio que asumir el desagradable deber de emprender una guerra que lleve el amor cristiano a pueblos oprimidos por la ignorancia y el mal hacer de sus dirigentes y sabios. Porque como decía San Agustín "si los infieles son adoctrinados pero no aterrorizados, endurecidos por la Antigüedad de sus costumbres, se inclinarán demasiado lentamente a entrar por el camino de la salva-

Segusio el «Ostiense» o el comentario a las Decretales de Juan Andrés. Vid., p. 200, notas 20 y 21 de la edición citada.

45 Apologia..., 9.2-3.

46 Apología... 10.2

47 Apología.. 13.2. La cita de Aristóteles corresponde a Etica Nicomaquea, X.9 donde se trata el tema de si es posible o fácil transformar por medio de la razón hábitos antiguos arraiyados en el carácter.

${ }_{48}$ Sepúlveda se adhiere aquí a la idea postulada por la Escuela de Salamanca en general. Tanto Vitoria en sus Relecciones teológicas (Del aumento y disminución de la caridad) como de Soto en el libro II de su De lustitia et de lure interpretan las ideas tomistas sobre la virtud en clave absolutamente aristotélica afirmando que la virtud es una forma de 
Pasiones políticas e imperialismo: la polémica entre Ginés de Sepúlveda...

ción». En opinión del santo de Hipona, la dominación violenta contra los infieles sólo sería cruel si se les atemorizase y no se les instruyese. Sepúlveda parece suscribir plenamente esta opinión ${ }^{49}$.

Juan Ginés de Sepúlveda, de la mano tanto de Aristóteles como de San Agustín construye así un formidable modelo cuyos elementos están engarzados por medio de una lógica implacable: la lógica del amor/caridad llevada con maestría hasta sus últimos extremos. Al igualitarismo asimilacionista de Las Casas, Sepúlveda opondrá un orgulloso etnocentrismo. Pues así como el juicio de los virtuosos y prudentes es lo que determina la medida de la virtud, así también el Derecho Natural debe ser definido según los hombres doctos, de tal manera que son los pueblos de superioridad natural y ética los que deben determinar aquello que sea justo por naturaleza ${ }^{50}$. He aquí el punto clave de la discrepancia entre Sepúlveda y la teología jurídica dominante. El derecho natural que defiende es el derecho natural tal y como 10 entienden los pueblos civilizados, es decir cristianos. No es el derecho natural defendido por los teólogos de Salamanca del que participaban todos los hombres y pueblos por su mera cualidad de tales. Sepúlveda se niega a reconocer la capacidad de los indígenas para percibir lo más elemental del derecho natural al constatar, no ya que tienen costumbres caníbales y participan en ritos religiosos plagados de sacrificios humanos, sino que estas violaciones flagrantes de la racionalidad humana se realizan abiertamente y son alentadas desde las institucio-

\footnotetext{
ser que se adquiere por medio de los hábitos correctos. Porque consiste en saber elegir correctamente, lo que sólo se aprende por medio de la práctica. La definición de virtud como forma de ser se encuentra en Aristóteles en Etica Nicomaquea libro II. cap.5. Todos los ejemplos mencionados en el texto también son del Estagirita y pueden consultarse en la misma obra, libro Il. cap.1, 1103a30ss.

49 Vid. Epistola 93 a Vicente, donde el santo defiende la necesidad de cazotes paternales" (paterna flagella). El mismo tenor se aprecia en la carta 185 dirigida al conde Bonifacio a principios del año 417 de nuestra Era.

so Sobre la superioridad de ciertos pueblos que determinan así el contenido del derecho natural vid. Demócrates Primero, I.XI: "Cum aliquid igitur hominum communi sententia honestum vel turpe, iustum aut vicissim iniustum esse dicimus, prudentium, studiorumque iudicia volemus intelligi, non etiam perditorum et pravis tum opinionibus tum etiam moribus corruptorum: nec si qua gens est adeo barbara et inhumana, ut a sensu communi hominum abhorreats., pp. 236-7 de la edición latina citada. Asimismo vid. De fato et de libero arbitrio, I.XVII, p. 482 donde afirma que las cosas deben hacerse según las hacen quienes saben hacerlas (quibus in rebus versetur) y Cohortatio ad Carolum V, V.X., (pg. 365 de la edición latina de las Opera, Vol. IV) donde define lo que entiende por una república cristiana bien ordenada, regida por la ley natural según lo que los sabios entienden que es la ley natural.
} 
nes públicas, desde una traditio defectuosa que sólo puede ser erradicada acabando con sus custodios: los sabios y los poderosos de la comunidades indígenas. La fuente directa de su teoría es, sin duda Aristóteles, un Aristóteles leído directamente al que difícilmente cabe reconciliar en este punto con la visión estoico/cristiana según la cual la Ley Eterna imprime directamente el derecho natural en toda criatura racional. En una de las cartas de Ginés de Sepúlveda que conservamos comenta: "El derecho natural da pues la razón a aquellos pueblos que, por simples motivos de generosidad, se lanzan a implantar su dominio sobre pueblos bárbaros, no con el fin de obtener un provecho material...sino más bien para cumplir un deber de humanidad al desarraigar sus costumbres tan contrarias al derecho natural.." ${ }^{51}$. No sabremos nunca hasta qué punto pudo ser consciente de la implacabilidad que generaban sus presupuestos. Al fin y a la postre todo podía quedar justificado por el cumplimiento de una razón de amor que, parafraseando el Cantar de los Cantares, resultaba ser «más fuerte que la muerte».

\section{EL UNIVERSALISMO DESPÓTICO DEL AMOR ABSOLUTO}

¿Universalismo tolerante o universalismo etnocéntrico? ¿Asimilación o reeducación? ¿Fuerza o argumento? Tanto Las Casas como Sepúlveda manifestaban la pretensión de desplegar en el contacto con «los otros» el orden, el amor y la solidaridad. Afirmaban que sus modelos respectivos reflejaban un sentimiento auténtico de cooperación a través de la justicia. Por decirlo con Paul Ricouer, ${ }^{52}$ intentaban tender un puente entre la poética del amor y la prosa de la justicia, haciendo de los preceptos y las leyes algo más que un escudo defensivo frente a la codicia y el arısia de dominio de los demás. A pesar de sus diferencias ambos se muestran de acuerdo en muchas cosas. En hacer del amor cristiano el pilar fundamental de las virtudes políticas, por ejemplo. En la necesidad de contemplar el interés y tutela de los paganos, en el desprecio a la conquista por motivos «egoístas". En el hecho de que es menester atribuir un papel central a la idea de tradición de los pueblos. También coinciden en el repudio de la tradición,

51 Carta dirigida a Francisco de Argote. Cfr., LoSADA, A. (edt.), Epistolario de Juan Ginés de Sepúlveda. Madrid, 1979, p.192.

52 En palabras de Ricoeur, P., Amore e giustizia. Brescia, 2000, p.31. 
de los sistemas de valores y creencias de los propios indios. A éstos simplemente no se les permite plantearse de acuerdo con sus propios presupuestos y cultura la aceptación o el rechazo de los foráneos, no se tienen en cuenta sus reglas del juego. Porque en la empresa colonizadora se siguen unos principios, un derecho y una teología: la de los conquistadores. Por "presunción civilizatoria» religión, lo que se dice religión sólo cabía una: la católica. Fuera de ella habia prácticas religiosas, pero no religión, costumbres jurídicas pero no derecho legitimo y con autoridad propia ${ }^{53}$.

Se ha señalado que en realidad, cabría reducir las discrepancias entre Sepúlveda y Las Casas a un simple problema de ordenación, a saber, ¿qué es primero la conversión o el sometimiento a la jurisdicción de la Corona? ${ }^{54}$ Lo cierto es que esta cuestión acabará siendo verdaderamente espinosa y tal vez podría plantearse como un problema general de las comunidades cristianas de la época que afectaba, antes que a su relación con otras culturas, a las teorías sobre la ordenación interna adecuada y podía llegar a generar sentimientos contradictorios en los individuos. ¿Qué se debe ser en primerísimo lugar, católico o ciudadano? ¿Dónde debían residir las lealtades más firmes, los principios más inconmovibles? ${ }^{55}$ Uno siente la tentación de afirmar que la república cristiana de Las Casas y de Sepúlveda precisaba más de santos que de ciudadanos. De santos, eso si capaces de establecer en el plano secular un nuevo orden cívico basado en las virtudes cristianas del amor y la solidaridad. De santos ciudadanos que emprendieran la lucha a favor de creación de una nueva comunidad universal, que entendiera la política como una evolución de perfección moral escatológica: desde el «barbarismo" del pecado de los indígenas a la «perfección moral» cristiana.

Ambos modelos descansan sobre una moralidad ideal y sin mácula cuyos presupuestos, teóricamente irrefutables, son la sanción religiosa

53 Sobre estos aspectos vid. Todorov, T., Las morales de la historia. Barcelona, 1993, pp. 61-2, y también ClAVERO, B., Derecho indígena y cultura constitucional en América. Méjico, 1994, pp. 5-10.

54 El problema se plantea en estos términos por KIMMINICH, O., "Die Entstehung des neuzeitlichen Völkerrechts", en I. Fetscher y H. Münkler (eds), Pipers Handbuch der politischen Ideen, Vol. III, Munich, 1985, pp. 73-100. La cita concreta en la p. 83.

55 Sobre este tema vid. Fernández Albaladejo, P., "Católicos antes que ciudadanos: gestación de una "política española" en los comienzos de la Edad Moderna" en J.I. Fortea Pérez (ed), Imágenes de la diversidad: el mundo urbano en la Corona de Castilla (siglos xviXVIII). Cantabria, 1997. 
de la ley de Dios y la fe en un futuro cierto en el que se repartirán premios y castigos a los cristianos. Se basa, por tanto en "verdades evidentes o «reveladas», inasequibles a la demostración práctica o la persuasión política. Al ser "evidentes" estas verdades resultan ser pre-racionales, estar más allá del argumento. Su obligatoriedad resulta, por tanto, tan poco justificable como los mandatos de un poder despótico o los axiomas matemáticos. Más aún, desde esa perspectiva neoplatónica que tiende a considerar la tendencia a la unidad el mayor de los bienes, el amor a Dios se convierte en la única perspectiva válida. Los miembros de la sociedad política, esa comunidad social con fines morales de Aquino, al desplegar sus capacidades amorosas y solidarias, empiezan a comportarse como miembros de una gran familia, multiplicando y prolongando su forma de ver el mundo. Ciegos y sordos ante otros argumentos que no sean los propios, atentan contra lo que la teoría política clásica ha tendido a considerar el rasgo fundamental de la esfera pública: la diversidad. Si nos mostramos de acuerdo con los teóricos greco/romanos en que la esfera público/política extrae su importancia de la posibilidad de exponer públicamente distintas formas de ver el mundo y de interpretarlo. Si aceptamos que sólo cuando podemos considerar un hecho, un suceso, desde distintos puntos de vista, podemos llegar a adquirir certeza sobre su realidad e importancia, entonces debemos considerar con cierta suspicacia todos aquellos modelos que, en busca de una unicidad tal vez imposible, intenten suprimir toda expresión de opinión divergente. Porque como bien señalara Hannah Arendt, la fusión de lo múltiple en busca de la unicidad resulta ser básicamente "anti-política" al destruir la especificidad de cada ser humano, al eliminar la diferencia en los puntos de vista y la capacidad de argumento ${ }^{56}$.

Cuando la creación de una sociedad ideal, por mucho que sus fundameritos últimos sean valores que tendamos a considerar positivos como la solidaridad o la compasión, requiere de la despiadada pedagogía de un Ginés de Sepúlveda o de la condescendiente asimilación de un Bartolomé de las Casas, quizá debamos hacer sonar la voz de aiarma. Porque como sabemos desde tiempos de Eurípides, hay amores que matan y no sólo en sentido metafórico. En el plano de la política tenemos experiencias lo suficientemente recientes como para re-

56 Vid. Arendt, H., The Human Condition. Chicago, 1959, pp. 214-15 
cordarnos que ha habido utopías que han acabado revirtiendo en su contrario. Quizá debamos rescatar del olvido a todos aquellos pensadores que desde antiguo nos advierten sobre las bondades del equilibrio y los peligros del exceso. Aunque se trate de excesos de amor. Porque pensadores como Juan Ginés de Sepúlveda nos hacen dudar de esa idea tan extendida de que la justicia pacifica por medio de la disciplina, mientras que el amor pacifica por el consenso ${ }^{57}$. Puede que el problema no esté en el amor sino en la tentación de convertirlo en absoluto. Habría entonces que darle la razón a Albert Camus cuando afirmaba que el bien absoluto o el mal absoluto, si se pone en ello la lógica necesaria, requieren del mismo furor. Pudiera ser que la reflexión sobre estos problemas de épocas pasadas nos inviten a extraer una lección de prudencia en un mundo como el nuestro uno de cuyos rasgos definitorios parece ser la globalización.

57 La frase es de Hespanha, A., "La senda amorosa del derecho" en C. Petit (ed), Pasiones del jurista: amor, memoria, melancolia, imaginación. Madrid, 1997, p. 26. 